\title{
THE EFFECTIVENESS OF DIFFERENT INSECTICIDE PROGRAMMES FOR KIWIFRUIT
}

\author{
C.E. McKENNA
}

\author{
HortResearch, TePuke Research Centre, RD2, Te Puke
}

\begin{abstract}
The levels of leafroller and armoured scale control achieved using six different spray programmes were compared against an unsprayed control. Test programmes included post-blossom applications of Bacillus thuringiensis $(B t)$ only, diazinon only, and a combination of the two. The effect of a pre-blossom diazinon spray or spring oil application on subsequent armoured scale populations was also measured. Three sprays of $B t$ in December-January provided excellent control of leafrollers for the entire season. Using diazinon instead of $B t$ resulted in high levels of leafroller damaged fruit, and live caterpillars in the crop at harvest. The risk of late-season armoured scale infestations on leaves or fruit was greater when no diazinon sprays were applied post-blossom. An additional pre-blossom diazinon spray had no effect on subsequent pest levels.
\end{abstract}

Keywords: kiwifruit, leafrollers, armoured scale insects, spray programmes.

\section{INTRODUCTION}

Leafrollers (Lepidoptera: Tortricidae) are the most damaging pests of kiwifruit. Several species can be found on kiwifruit vines but the most important are the brownheaded leafroller (Ctenopseustis obliquana) and the black-lyre leafroller (Cnephasia jactatana) (Steven 1992).

The majority of leafroller damage to kiwifruit occurs in the eight weeks immediately post-blossom, i.e. December-January (Stevens et al. 1995). To protect the crop over this critical damage period, it is recommended that three insecticide sprays are applied at intervals of two to three weeks. These sprays are the core of the pest control programme for kiwifruit, and in their absence fruit losses due to caterpillar feeding can exceed 30\% (Steven 1990; McKenna et al. 1995). The rate of new damage from leafrollers declines rapidly from February to harvest in May. During this period sprays against leafrollers are only applied if monitoring shows the crop to be at risk.

Insecticide use in the post-blossom spray programme is restricted by withholding periods as set by the exporting authority. Pirimiphos-methyl/permethrin or diazinon/ permethrin can only be applied immediately after fruit set, while diazinon may be used up to about the end of January depending on the intended harvest date. Bacillus thuringiensis $(B t)$ products have a nil withholding period and their use is not restricted.

It is estimated that $50 \%$ of growers applied only diazinon during the critical postblossom period in 1996-97 (E. Harre pers. comm.). However, there is considerable anecdotal evidence that suggests a spray programme which incorporates at least one application of $B t$, pirimiphos-methyl/permethrin or diazinon/permethrin gives better crop protection from leafrollers. Discussions with growers and supervisors of Pest Monitoring Centres in the Bay of Plenty revealed that the majority of leafroller problems occurred in orchards that received only diazinon post-blossom. This study aimed to quantify the relationship between the level of leafroller control achieved, and the type of insecticide used in the post-blossom spray programme.

The other key pests of kiwifruit are two species of armoured scale insects (Homoptera: Diaspididae). The choice of insecticide used early-season also influences armoured scale control, so the effect of the different spray programmes on subsequent armoured scale populations was also investigated. 


\section{Small-plot field trial}

\section{METHODS}

The trial was carried out at the Te Puke Research Orchard in a mature block of kiwifruit, cv. Hayward, trained on a T-bar structure. The effectiveness of six different spray programmes for leafroller and armoured scale control was compared with an unsprayed control (Table 1). In two treatments which used three sprays of $B t$ for leafroller control, spray(s) of mineral oil were included for early-season armoured scale control. Chemicals were applied at the full recommended rates; diazinon (Basudin 50WP), 50g/100 litres; Bt (Dipel 2X), 50g product/100 litres and mineral oil (Sunspray Ultra-Fine), $1 \%$ v/v. Sprays listed in Table 1 were the only insecticides applied to the vines for the entire growing season.

A plot was a single vine and there were five replicates in a randomised block design. Sprays were applied to runoff (approximately 6 litres/vine) using a handgun from a small-plot sprayer.

\section{TABLE 1: Treatment spray programmes showing insecticide used and application dates.}

\begin{tabular}{lcllllll}
\hline Treatment & $\begin{array}{c}\text { Pre-blossom } \\
\text { sprays }\end{array}$ & \multicolumn{5}{c}{ Post-blossom spray programme } \\
\hline 1 & - & $5.12 .96^{1}$ & $B t$ & 18.12 .96 & $B t$ & 6.1 .97 & $B t$ \\
2 & - & 5.12 .96 & $B t+$ oil & 18.12 .96 & $B t$ & 6.1 .97 & $B t$ \\
3 & - & $9.12 .96^{2}$ & diaz & 23.12 .96 & diaz & 13.1 .97 & diaz \\
4 & - & 5.12 .96 & $B t$ & 18.12 .96 & diaz & 8.1 .97 & diaz \\
5 & 7.10 .96 oil & 5.12 .96 & $B t+$ oil & 18.12 .96 & $B t$ & 6.1 .97 & $B t$ \\
6 & $14.11 .96 \mathrm{diaz}$ & 9.12 .96 & diaz & 23.12 .96 & diaz & 13.1 .97 & diaz \\
7 & unsprayed control & & & & & & \\
\hline
\end{tabular}

${ }^{1}$ Estimated $90 \%$ petal fall

${ }^{2}$ Bees removed from orchard previous night.

Fifty fruit per plot were picked on 3.2.97 and scored for caterpillar damage. Another 100 fruit per plot were similarly assessed at harvest on 8.5.97. Two damage categories were used: 1) light $=$ superficial damage $<1 \mathrm{~cm}^{2}$; and 2) severe $=$ superficial damage $>1 \mathrm{~cm}^{2}$ and any penetrating damage (non-export).

Between the two assessment dates, 20 fruit clusters per plot were checked monthly in situ for any caterpillar activity (live caterpillars and/or fresh feeding damage). These checks were made on 4.3.97 and 1.4.97.

Armoured scale levels were monitored three times during the growing season (11.2.97, 5.3.97 and 1.4.97). At each sample date, 20 leaves per plot were picked and examined under a stereomicroscope for live and dead armoured scale. In addition, the 100 fruit per plot picked on 8.5.97 were similarly assessed for scale infestation.

Analyses of variance and LSD tests using angular transformed percentages of damaged or infested fruit were carried out in order to detect statistical differences between treatments. Data presented in the results are means calculated from raw percentages. Statistical significance is given at the 5\% level.

\section{Spray diary analysis}

A random sample of 503 grower spray diaries was analysed to further investigate the relationship between the type of insecticide used in the post-blossom spray programme (December-January), and the incidence of caterpillar infestations during the later half of the season (February-May). An application of one or more Bt sprays during the FebruaryMay monitoring period indicated that a caterpillar infestation had occurred.

\section{Leafroller control}

\section{RESULTS}

Spray programmes based on three post-blossom applications of $B t$ provided excellent leafroller control. The mean percentages of fruit with caterpillar damage in 
these treatments were significantly lower than in the unsprayed control at both assessment times (Table 2). In contrast, three post-blossom applications of diazinon failed to protect the crop, and resulted in levels of leafroller damage at harvest which were not significantly different from those recorded in the unsprayed control. The inclusion of a pre-blossom diazinon application (treatment 6) helped reduce the amount of early season crop damage, but this effect was no longer apparent at harvest. A better result was achieved when $B t$ was used instead of diazinon for the first postblossom spray (treatment 4 ). This treatment gave a significant reduction in early season damage that was sustained through to harvest.

TABLE 2: Mean percentages of severe and total caterpillar-damaged fruit at the interim and harvest assessments.

\begin{tabular}{lrrlrl}
\hline & \multicolumn{2}{c}{ Severe damage $(\%)$} & \multicolumn{2}{c}{ Total damage $(\%)$} \\
Treatment & Interim & Harvest & Interim & Harvest \\
\hline 1. $B t, B t, B t$ & $1.2 \mathrm{~b}^{1}$ & $1.2 \mathrm{~b}$ & $4.4 \mathrm{~b}$ & $5.2 \mathrm{c}$ \\
2. $B t+$ oil, $B t, B t$ & $2.4 \mathrm{~b}$ & $2.2 \mathrm{~b}$ & $2.8 \mathrm{~b}$ & $5.2 \mathrm{c}$ \\
3. diaz, diaz, diaz & $11.2 \mathrm{a}$ & $20.6 \mathrm{a}$ & $15.2 \mathrm{a}$ & $27.2 \mathrm{a}$ \\
4. $B t$, diaz, diaz & $5.2 \mathrm{~b}$ & $3.4 \mathrm{~b}$ & $7.2 \mathrm{~b}$ & $10.0 \mathrm{bc}$ \\
5. (oil) $)^{2}, B t+$ oil, $B t, B t$ & $1.6 \mathrm{~b}$ & $1.6 \mathrm{~b}$ & $3.2 \mathrm{~b}$ & $6.8 \mathrm{c}$ \\
6. (diaz), diaz, diaz, diaz & $4.0 \mathrm{~b}$ & $11.4 \mathrm{a}$ & $5.6 \mathrm{~b}$ & $18.0 \mathrm{ab}$ \\
7. unsprayed control & $14.4 \mathrm{a}$ & $18.8 \mathrm{a}$ & $17.6 \mathrm{a}$ & $26.4 \mathrm{a}$ \\
\hline
\end{tabular}

${ }^{1}$ Within a column means with the same letter are not significantly different $(\mathrm{P}>0.05)$.

${ }^{2}$ Brackets indicate pre-blossom application.

The numbers of fruit with caterpillar damage in the unsprayed and diazinon treated plots increased markedly between the interim and harvest assessments, while the counts of damaged fruit in the plots sprayed with $B t$ showed little or no increase (Table 2 ). This result was consistent with the levels of caterpillar activity detected during in situ checks of fruit clusters, and at the harvest assessment. High numbers of live caterpillars and/or fresh feeding damage were only recorded in treatments which did not receive a post-blossom Bt application (Table 3).

TABLE 3: Mean percent caterpillar activity found during in situ fruit checks and at the harvest assessment.

\begin{tabular}{|c|c|c|c|}
\hline \multirow[b]{2}{*}{ Treatment } & \multicolumn{3}{|c|}{ Fresh damage and/or live caterpillars $(\%)$} \\
\hline & 4.3.97 & 1.4 .97 & 8.5 .97 \\
\hline 1. $B t, B t, B t$ & 0 & 0 & $0 \mathrm{c}^{1}$ \\
\hline 2. $B t+$ oil, $B t, B t$ & 0 & 0 & $0 \mathrm{c}$ \\
\hline 3. diaz, diaz, diaz & 1 & 4 & $4.8 \mathrm{a}$ \\
\hline 4. $B t$, diaz, diaz & 0 & 0 & $1.0 \mathrm{bc}$ \\
\hline 5. $(\text { oil })^{2}, B t+$ oil, $B t, B t$ & 0 & 0 & $0.8 \mathrm{bc}$ \\
\hline 6. (diaz), diaz, diaz, diaz & 0 & 6 & $3.4 \mathrm{a}$ \\
\hline 7. unsprayed control & 1 & 5 & $2.6 \mathrm{ab}$ \\
\hline
\end{tabular}

${ }^{1}$ Within a column means with the same letter are not significantly different $(\mathrm{P}>0.05)$.

${ }^{2}$ Brackets indicate pre-blossom application.

Analysis of 503 grower spray diaries confirmed there was a link between the type of insecticide used in the post-blossom spray programme and the number of $B t$ sprays required during the February to May period. Just over $60 \%$ of 257 growers who used three sprays of diazinon post-blossom later experienced leafroller problems that necessitated $B t$ applications. In contrast, only $15 \%$ of 246 growers who used $B t$, 
pirimiphos-methyl/permethrin or diazinon/permethrin, instead of diazinon for the first post-blossom spray, needed to apply further sprays against leafrollers. A preblossom organophosphate application was listed on over half the spray diaries, but this practice did not affect the percentage of growers applying $B t$ during February-May.

Spray diaries from organic growers were not included in the analysis because of the small sample size $(n=30)$. These growers applied two or three $B t$ sprays in December-January and these were the sole applications required against leafrollers for the entire season.

\section{Armoured scale control}

Vines used in this trial had not received any insecticide applications against armoured scale insects for several seasons and pest pressure at the site was accordingly high. No mineral oil or diazinon sprays were applied in treatment one, and it was therefore regarded as a second control in the analysis.

At the first leaf sample all treatment spray programmes had significantly fewer leaves with live armoured scale compared with the unsprayed controls (Table 4). Sprays of mineral oil or diazinon reduced levels of leaf infestation by $57-85 \%$ relative to the controls, but there was only one significant difference among the spray treatments. A single mineral oil spray resulted in significantly more scale-infested leaves than three or four diazinon applications.

Levels of armoured scale on the leaves remained relatively static between the first and second sample dates, but by early April further armoured scale settlement had occurred in some treatments, as demonstrated by the increased levels of scale-infested leaves in the final sample (Table 4). The greatest increase was recorded in the treatment which had received a single mineral oil application. In this treatment, the percentage of leaves infested with live armoured scale almost trebled from the previous sample date, and was no longer statistically distinguishable from the unsprayed controls. Levels of leaf infestation also increased in the treatments which received two diazinon or two mineral oil sprays, but they remained significantly lower than those in the controls.

\section{TABLE 4: Mean percent of leaves infested with scale (live only) at each sample date and the mean percent of fruit infested with scale (live and dead) at harvest.}

\begin{tabular}{lcccc}
\hline & \multicolumn{3}{c}{$\begin{array}{c}\text { Leaves infested with } \\
\text { live scale (\%) }\end{array}$} & $\begin{array}{c}\text { Fruit infested } \\
\text { with scale (\%) }\end{array}$ \\
Treatment & 11.2 .97 & 5.3 .97 & 1.4 .97 & \\
\hline 1. $B t, B t, B t$ & $64 \mathrm{a}^{1}$ & $63 \mathrm{a}$ & $69 \mathrm{a}$ & $33.2 \mathrm{ab}$ \\
2. Bt + oil, Bt, Bt & $29 \mathrm{~b}$ & $22 \mathrm{~b}$ & $62 \mathrm{ab}$ & $24.2 \mathrm{bc}$ \\
3. diaz, diaz, diaz & $11 \mathrm{c}$ & $22 \mathrm{~b}$ & $30 \mathrm{c}$ & $11.8 \mathrm{de}$ \\
4. Bt, diaz, diaz & $19 \mathrm{bc}$ & $16 \mathrm{~b}$ & $41 \mathrm{c}$ & $13.4 \mathrm{cde}$ \\
5. (oil) $)^{2}, B t+$ oil, $B t, B t$ & $22 \mathrm{bc}$ & $21 \mathrm{~b}$ & $48 \mathrm{bc}$ & $18.0 \mathrm{~cd}$ \\
6. (diaz), diaz, diaz, diaz & $10 \mathrm{c}$ & $28 \mathrm{~b}$ & $28 \mathrm{c}$ & $6.0 \mathrm{e}$ \\
7. unsprayed control & $68 \mathrm{a}$ & $63 \mathrm{a}$ & $71 \mathrm{a}$ & $40.6 \mathrm{a}$ \\
\hline
\end{tabular}

${ }^{1}$ Within a column means with the same letter are not significantly different $(\mathrm{P}>0.05)$. ${ }^{2}$ Brackets indicate pre-blossom application.

Treatments which resulted in the lowest levels of leaf infestation in April also had the lowest percentages of scale-infested fruit at harvest (Table 4). With the exception of treatment 2 (single mineral oil spray), all insecticide treatments resulted in significantly fewer fruit with scale compared to the unsprayed controls. Spray programmes which included two or more applications of diazinon provided the most effective scale control. In these treatments scale-infested fruit ranged from $6.0 \%$ (four diazinon applications) to $13.4 \%$ (two diazinon applications) but these differences were not significant. Applying both a pre- and post-blossom mineral oil spray resulted 
in a slightly higher level of fruit infestation (18\%), but this result could not be distinguished statistically from treatments which used two or three diazinon sprays.

\section{DISCUSSION}

This study has demonstrated the importance of the type of insecticide used in the post-blossom spray programme in preventing economic damage from leafrollers and armoured scale insects. It has also raised questions about the efficacy of diazinon against leafrollers.

The absence of significant crop damage in treatments based on $B t$ applications has confirmed that three sprays of $B t$ in December-January are sufficient for effective control of leafrollers over the entire season. In contrast, the levels of leafroller damaged fruit on vines sprayed only with diazinon were no different from those on unsprayed vines. More importantly, the occurrence of new leafroller damage after a spray programme of diazinon culminated in the presence of live caterpillars in the crop at harvest. These results, supported by the spray diary analysis, have provided unequivocal evidence that diazinon is failing to provide adequate control of leafrollers in kiwifruit orchards.

It had been suggested that the lack of leafroller control achieved with diazinon compared with $B t$ in commercial orchards may be related to the different application times of these sprays. Whereas the first $B t$ spray is normally applied at $75-90 \%$ petal fall, diazinon cannot be used until flowering has finished and bees have been removed from the orchard. In this trial, the five day difference between $75-90 \%$ petal fall and the finish of flowering was considered too short to be of consequence and does not explain the ongoing feeding damage that occurred during, and subsequent to, the period when diazinon sprays were being applied. A more likely reason for the fieldcontrol failure of diazinon would be the presence of a diazinon-resistant strain of brownheaded leafroller. This could have serious implications for pesticide use and preliminary dosage-mortality tests are underway.

An estimated $50 \%$ of growers used a post-blossom spray programme based on diazinon alone in 1996-97. Many of these growers are likely to have experienced significant levels of fruit loss due to caterpillar feeding and also faced an increased risk of crop contamination at harvest. The costs associated with poor leafroller control are high and pest control guidelines have since been revised.

The type of insecticide recommended for use in the critical December-January period was first considered. While there is clear evidence to support a recommendation of three early-season $B t$ applications against leafrollers, consideration must also be given to armoured scale control. This trial showed that replacing diazinon with $B t$ plus mineral oil in the post-blossom spray programme increases the risk of late-season armoured scale infestations on leaves and fruit. The application of additional mineral oil sprays in February and March reduces this risk, but, until new options are available for armoured scale control, a broad-spectrum insecticide should continue to be included in the post-blossom spray programme.

\section{ACKNOWLEDGEMENTS}

This study was funded by Zespri. Thanks to Pene Speechlay and Steven Owen for technical assistance, and to Zespri for providing access to grower spray diaries.

\section{REFERENCES}

McKenna, C.E., Stevens, P.S. and Steven, D., 1995. A new Bacillus thuringiensis product for use on kiwifruit. Proc. 48th N.Z. Plant Prot. Conf.: 130-134.

Steven, D., 1990. Entomology in kiwifruit. Pp 362-412 In: Kiwifruit Science and Management, I.J. Warrington, G.C. Weston (Eds); Ray Richards Publisher in association with the New Zealand Society for Horticultural Science.

Steven, D., 1992. Pest Lepidoptera of kiwifruit in New Zealand.Acta Hort. 297: 531536

Stevens, P.S., McKenna, C.E. and Steven, D., 1995. The timing of Lepidopteran damage to kiwifruit. Proc. 48th N.Z. Plant Prot. Conf:: 130-134. 